
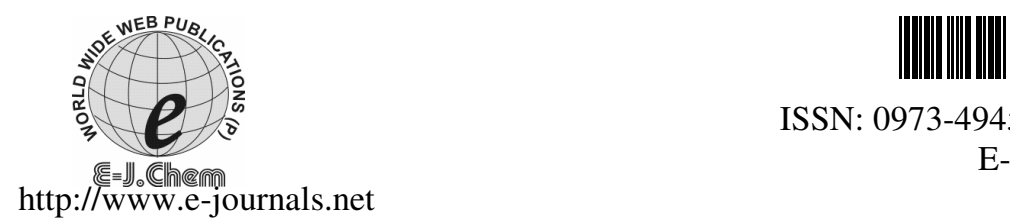

ISSN: 0973-4945; CODEN ECJHAO

E-Journal of Chemistry 2011, 8(1), 391-399

\title{
Simultaneous Determination by Gas Chromatography of Lindane and Carbaryl in Combined Formulations
}

\author{
INDRAJIT SEN, AJAY SHANDIL, MANJEET AGGARWAL and \\ RAKESH KUMAR KHANDAL*
}

Shriram Institute for Industrial Research

19 University Road, Delhi-110007, India

rkhandal@shriraminstitute.org

Received 18 January 2010; Revised 2 April 2010; Accepted 21 May 2010

\begin{abstract}
A gas chromatographic method developed and validated for simultaneous determination of lindane and carbaryl for quality evaluation of lindane-carbaryl granule, using a glass capillary HP5 column $(30 \mathrm{~m} \times 0.32 \mathrm{~mm}$; $0.25 \mu \mathrm{m})$, temperature programming with flame ionization detector and dibutylphthalate as an internal standard. The calibration graphs were found linear in the concentration range of $1 \mu \mathrm{g} / \mathrm{mL}$ to $1000 \mu \mathrm{g} / \mathrm{mL}$ for both lindane and carbaryl with correlation coefficient of 0.999 and 0.999 respectively and co-efficient of variation for intra-day and inter-day repeatability studies at different concentration levels was found to be less than $2 \%$. The accuracy of method ranges between $98.5 \%$ to $100.8 \%$. Specificity and robustness were also within the acceptable range. The method is highly sensitive with LOD and LOQ as 0.5 and $2 \mu \mathrm{g} / \mathrm{mL}$ for lindane and carbaryl respectively. The method has been tried on several formulations of lindane-carbaryl granules for quality control and has been found to be applicable.
\end{abstract}

Keywords: Gas chromatography, Carbaryl, Lindane, Combined formulation.

\section{Introduction}

Ever since the combination formulations consisting of more than one technical grade pesticide were allowed around a decade ago in India, there has been a large number of combination formulations being introduced in the market. The experience with the combination formulations has been encouraging, as their efficacy has been found to be better than the formulations containing single ingredient ${ }^{1}$.

Granules of lindane and carbaryl is one of the most widely used agrochemical formulation consisting of combination of two very important pesticide ingredients namely lindane and carbaryl present at concentration levels of $4 \%$ each. Lindane, also known as gamma-hexachlorocyclohexane 
$(\gamma-\mathrm{HCH})^{2}$ is an organochlorine chemical that has been used both as an agricultural insecticide and as a pharmaceutical treatment for infestations of lice and scabies ${ }^{3,4}$. Under the IUPAC system, lindane is named as gamma- $1 \alpha, 2 \alpha, 3 \beta, 4 \alpha, 5 \alpha$ and $6 \beta$-hexachlorocyclohexane, which is a white, odorless, crystalline solid with molecular weight of $290.82 \mathrm{~g} / \mathrm{mole}$ and molecular formula of $\mathrm{C}_{6} \mathrm{H}_{6} \mathrm{Cl}_{6}$ and chemical structure ${ }^{1,5}$ as shown in Figure 1a.

Carbaryl, named as per IUPAC as 1-naphthyl methyl carbamate is a white crystalline solid having molecular weight of $201.22 \mathrm{~g} / \mathrm{mole}$ and molecular formula of $\mathrm{C}_{12} \mathrm{H}_{11} \mathrm{NO}_{2}$ with the chemical structure ${ }^{1,6-8}$ as shown in Figure $1 \mathrm{~b}$.

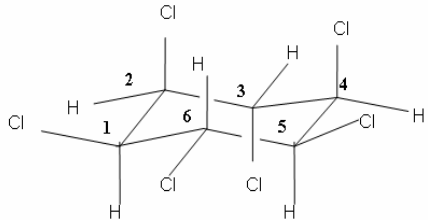

Figure 1a. Chemical structure of lindane (gamma- $1 \alpha, 2 \alpha, 3 \beta, 4 \alpha, 5 \alpha$ and $6 \beta$ hexachlorocyclohexane)

Carbaryl is widely used as an insecticide for home gardens, commercial agriculture and forestry ${ }^{9,10}$. Lindane-carbaryl granules (a colored formulation) is one of the most widely used agrochemical formulations. It has a broad range of insecticidal activity, contact stomach action, nervous and respiratory action ${ }^{11-16}$. The formulation is used for various crop pests in soil and agricultural fields ${ }^{17-21}$.

As there are no validated methods available in the literature for the simultaneous determination of both lindane and carbaryl, we have made an attempt to evaluate the quality of the combined granular formulation containing lindane and carbaryl with respect to the concentration of the active ingredients. Though there are methods available for the analysis of lindane in lindane containing formulation or carbaryl in carbaryl formulations as per CIPAC or WHO specification they do not mention about the analysis of combined lindane-carbaryl formulations ${ }^{22-28}$. On the other hand although Indian standard (IS) specification does have a protocol for analysis of lindane-carbaryl granules (IS: 11784:1986), two different methods are specified for the analysis of lindane and carbaryl respectively. For the analysis of lindane, the specification (IS: 882-1984) mentioned the gas chromatographic method using $\alpha$-naphthol as an internal standard, whereas for the analysis of carbaryl, spectrophotometric method is mentioned (IS: 7539-1975) ${ }^{29-35}$. The analysis of two components individually using two different methods is not only time consuming but it has also been observed that, during the gas chromatographic determination of lindane using $\alpha$-naphthol as an internal standard, produces inaccurate results. This is due to fact that $\alpha$-naphthol generally formed as an intermediate during the synthesis of carbaryl, is present as an impurity in the lindanecarbaryl formulation and thereby causes an interference with the accurate determination of lindane and carbaryl when internal standard used is also $\alpha$-naphthol.

The aim of the present work was to develop and validate an analytical method using a gas chromatographic technique for simultaneous determination of both lindane and carbaryl which is comparatively faster with significant precision, accuracy and resolution.

\section{Experimental}

The reference standards lindane (purity: 99\%) and carbaryl (purity: 99\%) were obtained from Sigma-Aldrich (USA). Dibutyl phthalate having purity $99 \%$ was procured from Fluka chemicals 
(USA) and acetone (HPLC grade) was purchased from SD fine chemicals, Mumbai, India. Formulations (within their shelf life) of lindane-carbaryl granules of commercial grade were procured from the local market. All chemicals were used as received.

Gas chromatography analysis was carried out using VARIAN-CP-3800 Gas Chromatograph equipped with split/splitless injector, a flame ionization detector was used for the measurements and glass capillary HP-5, ID: $0.32 \mathrm{~mm}$, length: $30 \mathrm{~m}$, film thickness: $0.25 \mu \mathrm{m}$; packed with non-polar polymer [(5\%-phenyl)-methylpolysiloxane]. Mettler weighing balances with a least count of $0.0001 \mathrm{~g}$ and $0.001 \mathrm{mg}$ for weighing of samples and standards respectively. Calibrated 'A' grade glassware of borosil procured from local market.

\section{Preparation of internal standard stock solution (A): Dibutyl phthalate (DBP)}

Approximately $0.5 \mathrm{~g}$ of dibutyl phthalate was accurately weighed and transferred into $100 \mathrm{~mL}$ volumetric flask, dissolved and diluted to volume using HPLC grade acetone.

\section{Preparation of reference standard solutions $(B)$}

Approximately $2.5 \mathrm{mg}$ each of reference standard of lindane and carbaryl were weighed accurately and transferred into $25 \mathrm{~mL}$ volumetric flask. To this $2.5 \mathrm{~mL}$ of internal standard stock solution (A) was added using a pipette and total volume was made up to the mark by HPLC grade acetone.

\section{Preparation of sample solutions $(C)$}

Approximately $60 \mathrm{mg}$ each of the seven formulations coded as 1 to 7 (lindane $4 \%$ and carbaryl $4 \%$ formulations) were accurately weighed individually and transferred into seven different $25 \mathrm{~mL}$ volumetric flask. To this, $2.5 \mathrm{~mL}$ of internal standard stock solution (A) was added and the total volume was made up to the mark using HPLC grade acetone.

\section{Gas chromatographic conditions}

Column: Glass capillary HP-5, ID: $0.32 \mathrm{~mm}$, length: $30 \mathrm{~m}$; film thickness: $0.25 \mu \mathrm{m}$; Carrier gas: Nitrogen at a flow rate of $1.2 \mathrm{~mL} / \mathrm{min}$.; Injector mode: Split of 1:10; Injection volume: $1 \mu \mathrm{L}$; Injector temperature: $250{ }^{\circ} \mathrm{C}$; Oven temperature: Initial $180{ }^{\circ} \mathrm{C}(12 \mathrm{~min}) @ 30{ }^{\circ} \mathrm{C} / \mathrm{min}$, to $300{ }^{\circ} \mathrm{C}$ (12 min); Detector: Flame ionization detector at $300{ }^{\circ} \mathrm{C}$.

\section{Method development and validation}

The method was validated for the determination of lindane and carbaryl for the following parameters; specificity, linearity, precision, accuracy, limit of detection, limit of quantitation, robustness and ruggedness as per the ICH (International Conference on Harmonization) guidelines.

\section{Linearity}

Linearity of the method was determined by plotting a calibration curve for both lindane and carbaryl for concentration $v s$. detector response (area counts in $\mathrm{mV}$ ). For this purpose, a combined standard stock solution containing both lindane and carbaryl at concentration level $2500 \mu \mathrm{g} / \mathrm{mL}$ of each was prepared by dissolving about $62.5 \mathrm{mg}$ (accurately weighed) each of the reference standards in $25 \mathrm{~mL}$ of volumetric flask and made up to volume with HPLC grade acetone.

From the combined standard stock solution of lindane and carbaryl, aliquots of 10, 5, 2.5, 1.0, $0.5,0.1,0.05$ and $0.01 \mathrm{~mL}$ were taken into eight individual $25 \mathrm{~mL}$ volumetric flask. To all the flasks, $2.5 \mathrm{~mL}$ of the internal standard solution (solution B) was added and the total volume was made up to the mark with acetone. This gave a series of combined calibration standard solutions of lindane and carbaryl having concentrations of 1000, 500, 250,100, 50,10, 5 and $1 \mu \mathrm{g} / \mathrm{mL}$ of both the compounds. From each of these calibration standards $1 \mu \mathrm{L}$ was injected into the GC. The calibration curve obtained was subjected to regression analysis by the least square method to calculate the calibration equation and the correlation coefficient (r). 


\section{Specificity}

The specificity of the method was determined by analyzing the sample solution (solution $\mathrm{C}$ ) containing all the components i.e. lindane, carbaryl, $\alpha$-naphthol and the internal standard that is DBP. For this purpose $1 \mu \mathrm{L}$ of one of the sample solutions was injected into the gas chromatograph and the specificity of the method was measured in terms of the resolution between the two peaks.

\section{Precision}

The precision of the method was determined in terms of repeatability or reproducibility and intermediate precision studies. Repeatability was determined by evaluating five replicates of the three different concentrations i.e. 10,50 and $100 \mu \mathrm{g} / \mathrm{mL}$ of the combined calibration standard solution of lindane and carbaryl on the same day (intra-day) under the mentioned chromatographic conditions. The intermediate precision of the method was assured by performing the analysis on three different days (inter-day) and also by different analysts in the same laboratory (between analysts). Co-efficient of variation or the percent RSD was calculated in each case.

\section{Accuracy}

The accuracy of the method was evaluated by spiking different known concentrations of lindane and carbaryl into the pre-analyzed sample. One of the seven sample solutions containing approx. $100 \mathrm{ppm}$ each of carbaryl and lindane was spiked with varying standard concentrations of lindane and carbaryl i.e. $50 \mathrm{ppm}$ of each, $100 \mathrm{ppm}$ of each and $150 \mathrm{ppm}$ of each so as to give a total concentration of $150 \mathrm{ppm}, 200 \mathrm{ppm}$ and $250 \mathrm{ppm}$ of both lindane and carbaryl. $1 \mu \mathrm{L}$ of each of these solutions was injected onto gas chromatograph and the closeness of the results to the true value was determined.

\section{Robustness}

Robustness of the method was determined by analyzing the same sample under different conditions of method parameters such as two different makes of gas chromatograph, same column from two different manufacturers, different analysts, varying injection volume.

\section{Limit of detection and limit of quantitation}

For the measurement of limit of detection, standard deviation of the background was determined. Thereafter, standard solutions of very low concentration levels i.e. 0.5, 1.0, 2.0 and $5.0 \mu \mathrm{g} / \mathrm{mL}$ were injected till the signal obtained was thrice the standard deviation of the background. For the measurement of limit of quantitation again, known concentration of standard carbaryl and lindane solutions were injected till the signal obtained was reproducible for five replicate injections.

\section{Results and Discussion}

\section{Analysis of formulation for lindane and carbaryl content}

The chromatogram (Figure 2) for the combined standard solution containing $50 \mu \mathrm{g} / \mathrm{mL}$ of each lindane and carbaryl shows well resolved peaks for the both lindane (RT.5.9 min) and carbaryl (RT. 8.2 min.).

DBP used as internal standard elutes at retention time, 10.2 minutes. The chromatogram (Figure 3) for the seven samples of lindane-carbaryl granules also shows well resolved peaks for lindane, carbaryl and the internal standard. 


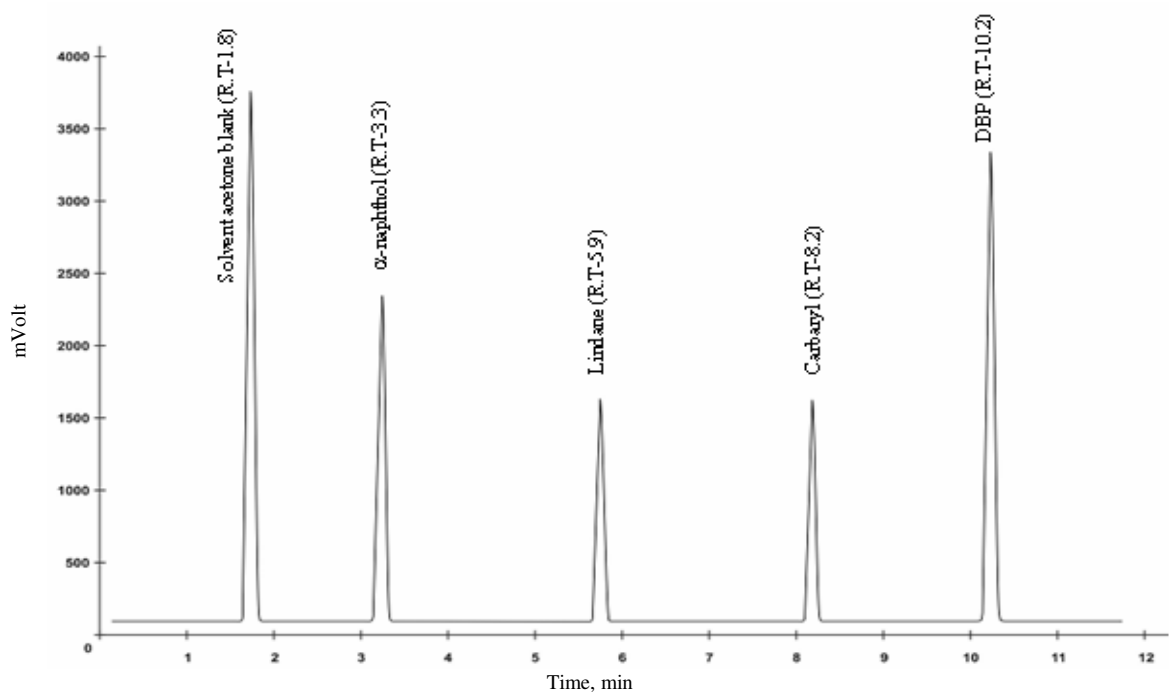

Figure 2. Gas chromatogram for standard solution containing lindane, carbaryl and DBP (Internal standard). Peak at R.T.3.3 min is due to $\alpha$-napthol (impurity from carbaryl)

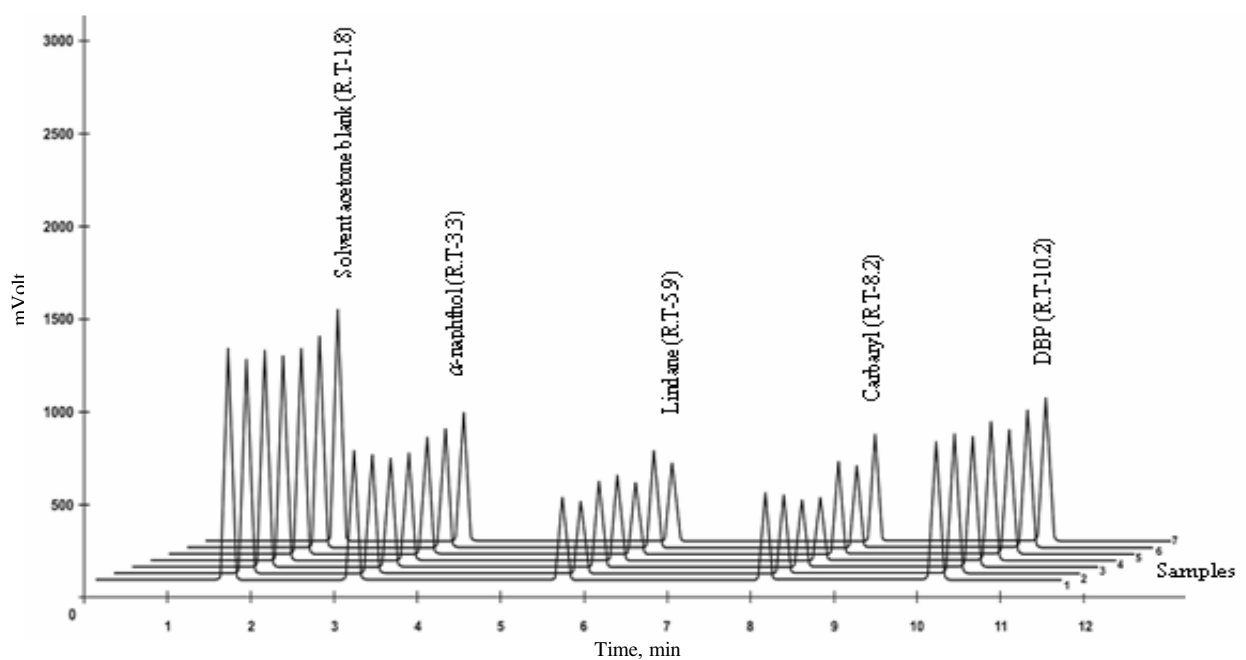

Figure 3. Gas chromatograms of seven sample solutions of lindane-carbaryl granules

On analysis of all the seven different formulations of lindane-carbaryl granules, the content for both lindane and carbaryl was determined and the results are presented in Table 1 . The results were found to be in agreement with the claim value of 4 percent each of both the pesticides. From the chromatogram of the seven samples, it can also be seen that besides the three peaks due to lindane, carbaryl and DBP, there is another peak at R.T $3.3 \mathrm{~min}$.

On analysis, it was found that this peak could be due to $\propto$-naphthol, which is normally present in carbaryl as an impurity (formed as an intermediate product) during the synthesis of carbaryl. This was further confirmed from the Gas chromatogram of the standard solution of $\propto$-naphthol (Figure 4). This observation further substantiates the apprehension about using $\propto$-naphthol as an internal standard (as specified in IS 117484:1986 for lindane-carbaryl granules) and this is why, the present method has been developed using DBP as an internal standard. 
Table 1. Percent purity of lindane and carbaryl in lindane-carbaryl granule formulations using the developed method

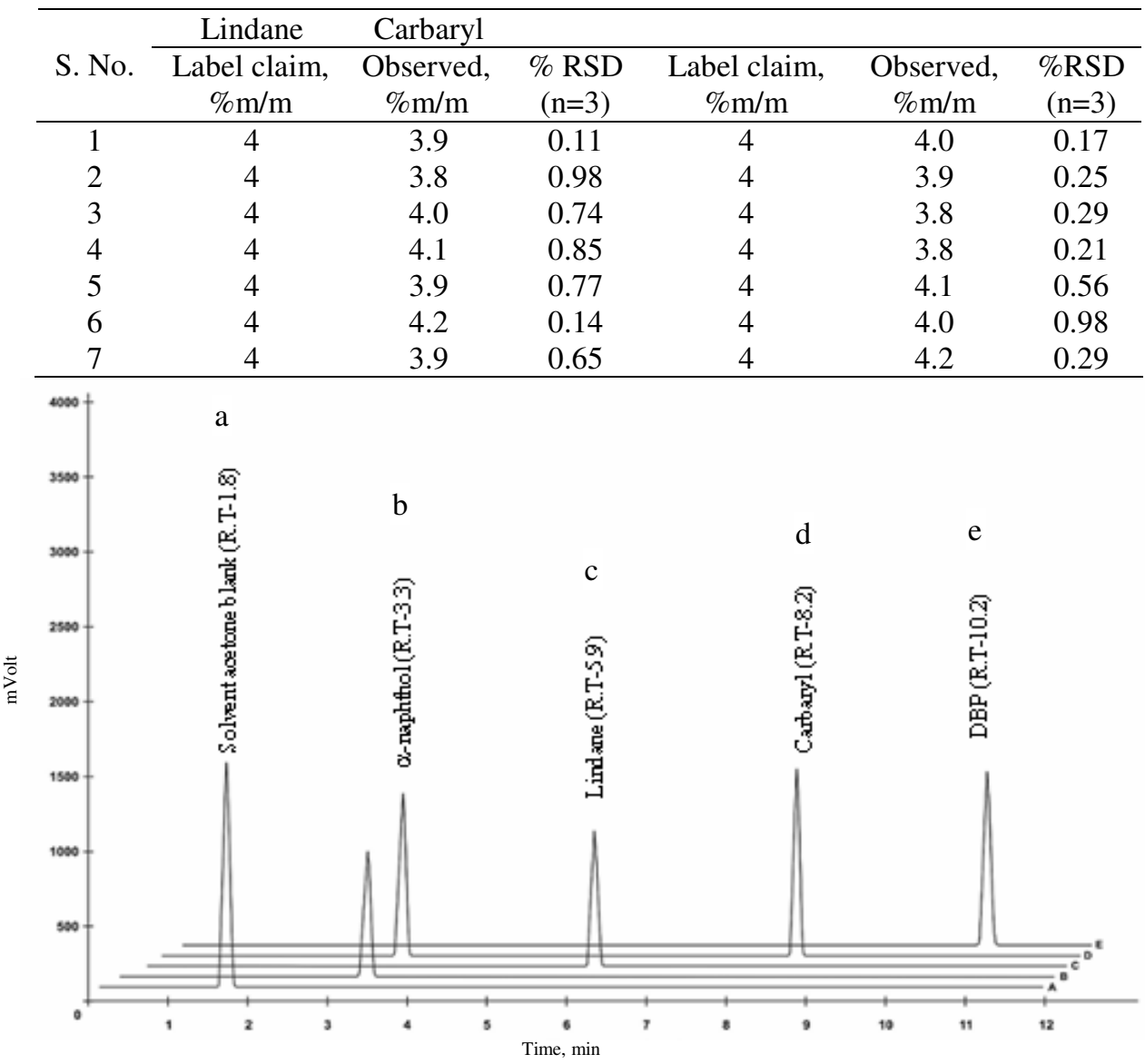

Figure 4. Chromatograms showing specificity of the method (a) acetone solvent blank (R.T.1.8 min); (b) $\alpha$-naphthol reference standard (R.T.3.3 min); (c) lindane reference standard (R.T.5.9 min); (d) carbaryl reference standard (R.T.8.2 min); (e) DBP Reference Standard (R.T.10.2 min)

\section{Validation of the developed method}

\section{Specificity}

The specificity of the method is indicated in Figure 4, which shows chromatogram for each of the individual components, i.e. lindane, carbaryl, DBP and $\propto$-naphthol. The peak corresponding to each component elutes at different retention times, thereby causing no overlapping of the peaks. Although, the formulation consists of $\propto$-naphthol as an impurity but the peak for $\propto$-naphthol does not interfere with the peaks due to lindane, carbaryl or DBP. The resolution factor $\left(R_{S}\right)$ values for the various component peaks were always $>2$, which clearly indicates that there is a complete separation of different components of the formulation when analyzed by the developed method. Thus, the specificity of the method can be considered as established as per the standard guidelines ${ }^{36}$ (International Conference on Harmonization). 


\section{Linearity}

Calibration graphs were plotted for the calibration range 1 to $1000 \mu \mathrm{g} / \mathrm{mL}$ for lindane and carbaryl. Both lindane and carbaryl gave linear response over the studied range of concentration and the least squares linear regression analysis of the data provided excellent correlation coefficient ( $r$ ) of more than 0.999 for both the compounds i.e. 0.9999 for lindane and 0.9998 for carbaryl.

\section{Accuracy}

Accuracy of the method evaluated on the basis of the comparison of the theoretical concentration level of the spiked solutions with the observed concentration gave acceptable and good percent recoveries of more than $98 \%$ for each spiked level (Table 2).

Table 2. Recovery studies for the determination of lindane and carbaryl by the developed method

\begin{tabular}{cccccc}
\hline Compound & $\begin{array}{c}\text { Original } \\
\text { concentration, } \\
\text { ppm }\end{array}$ & $\begin{array}{c}\text { Spiked } \\
\text { concentration, } \\
\text { ppm }\end{array}$ & $\begin{array}{c}\text { Total } \\
\text { concentration, } \\
\text { ppm }\end{array}$ & $\begin{array}{c}\text { Observed } \\
\text { concentration, } \\
\text { ppm }\end{array}$ & $\begin{array}{c}\text { Percent } \\
\text { Recovery } \\
\pm \text { RSD, n= 5 }\end{array}$ \\
\hline \multirow{3}{*}{ Lindane } & 99.32 & 49.42 & 148.74 & 146.49 & $98.49 \pm 0.18$ \\
& 99.32 & 98.84 & 198.16 & 196.65 & $99.24 \pm 0.22$ \\
& 99.32 & 148.26 & 247.58 & 245.94 & $99.34 \pm 0.17$ \\
Carbaryl & 101.58 & 49.5 & 151.08 & 150.84 & $99.84 \pm 0.32$ \\
& 101.58 & 99 & 200.58 & 197.46 & $98.44 \pm 0.26$ \\
& 101.58 & 148.5 & 250.08 & 246.99 & $98.76 \pm 0.54$ \\
\hline
\end{tabular}

\section{Precision}

Results obtained from the chromatographic analysis of the samples on the same day or intraday $(n=5)$ and on different days or inter day $(n=5)$ are given in Table 3 . The RSD values obtained were well below $2 \%$ for intra-day and inter-day precision for both the compounds, which is very well within the acceptable limits.

\section{Limit of detection and limit of quantitation}

The limit of detection (LOD) was calculated on the basis of $\mathrm{S} / \mathrm{N}$ (signal to noise) ratio of 1:3 and was found to be $0.5 \mu \mathrm{g} / \mathrm{mL}$ for both lindane and carbaryl. The limit of quantitation (LOQ) was obtained as $2.0 \mu \mathrm{g} / \mathrm{mL}$ evaluated on the basis of reproducible signal obtained on injecting 5 replicates of the same concentration.

Table 3. Intra-day and Inter-day precision studies for the determination of lindane and carbaryl by the developed method

\begin{tabular}{|c|c|c|c|c|c|}
\hline \multirow{2}{*}{ Compound } & \multirow{2}{*}{$\begin{array}{c}\text { Prepared } \\
\text { solution } \\
\text { concentration, } \\
\mu \mathrm{g} / \mathrm{mL}\end{array}$} & \multicolumn{2}{|c|}{$\begin{array}{c}\text { Intra-day } \\
\text { precision, } \mathrm{n}=5\end{array}$} & \multicolumn{2}{|c|}{ Inter-day precision, $\mathrm{n}=5$} \\
\hline & & $\begin{array}{c}\text { Observed } \\
\text { concentration, } \mu \mathrm{g} / \mathrm{mL}\end{array}$ & $\% \mathrm{RSD}$ & $\begin{array}{c}\text { Observed } \\
\text { concentration, } \mu \mathrm{g} / \mathrm{mL} \\
\end{array}$ & $\%$ RSD \\
\hline \multirow[t]{3}{*}{ Lindane } & 10 & 9.8 & 0.1 & 9.6 & 0.77 \\
\hline & 50 & 49.4 & 0.34 & 49.1 & 0.22 \\
\hline & 100 & 99.6 & 0.29 & 99.3 & 0.12 \\
\hline \multirow[t]{3}{*}{ Carbaryl } & 10 & 9.9 & 0.27 & 9.7 & 0.57 \\
\hline & 50 & 49.7 & 0.18 & 49.5 & 0.33 \\
\hline & 100 & 99.5 & 0.14 & 99.1 & 0.17 \\
\hline
\end{tabular}




\section{Robustness}

The method was found to be robust even with small changes in the analytical conditions; such as a change in gas flow rate $( \pm 0.01 \mathrm{~mL} / \mathrm{min})$, a change in temperature conditions of detector $\left( \pm 2{ }^{\circ} \mathrm{C}\right)$, a change in injector temperature $\left( \pm 2{ }^{\circ} \mathrm{C}\right)$, use of different gas chromatograph (Varian CP3800 and Agilent 6890) and use of same column from different manufacturers (HP5, DB5, CP-sil $8 \mathrm{CB}$ ). Under all of these conditions, the analytical value of the analytes in the test solution was not affected and was in accordance with the actual values as per the label claim.

\section{Conclusion}

A validated gas chromatographic method has been developed for the simultaneous determination of lindane and carbaryl in a combined granular formulation containing both lindane and carbaryl using dibutyl phthalate (DBP) as an internal standard. At present, the major constraint for the simultaneous determination of these two analytes is the nonavailability of a single validated method. The work described in this paper has shown that the analytical method developed is precise, accurate, sensitive and robust for the determination of both analytes. The method is specific to the analysis of lindane and carbaryl in the granule formulations without any interference from the other ingredients including the impurities such as $\propto$-naphthol present in the granules. The developed method was successfully applied to the simultaneous quantitative analysis of lindane and carbaryl in the combined formulation of lindane-carbaryl granules and therefore can be used for the routine quality control, ensuring efficiency and efficacy of the formulation for the desired purpose. Even though the method has been developed using granular formulation of combined pesticides, the same can be adopted without any further studies even for other type of formulations containing the combination of lindane and carbaryl.

\section{Acknowledgment}

The authors are thankful to the Management of Shriram Institute for Industrial Research for the guidance and support provided for undertaking the research study. The authors also thank Bayer's India Ltd. for providing the samples of Sevidol (combined formulation of lindane-carbaryl granules) for the purpose of evaluation for the analytical method development and validation.

\section{References}

1. Tomlin C D S, Pesticide Manual, British Crop Protection Council Publication, UK, 200, $10^{\text {th }}$ Ed., 1995.

2. Chan S, Kong M F, Wong Y C, Wong S K and Sin D W M, J Agric Food Chem., 2007, 55, 3339-3345.

3. Sun Feel, Lin Feng-Yi, Wong Sue-Sun and Li Gwo-Chen, J Food Drug Anal., 2000, 8(2), 103-111.

4. Kong M K, Chan S, Wong Y C, Wong S K and Sin W M, J AOAC Int., 2007, 90, 1133-1141.

5. Rodrigues M V N, Reyes F G R, Magalhães P M and Rath S, J Braz Chem Soc., 2007, 18(1), 135

6. Mohammad A Mottaleb and Mohammad Z Abedin, Anal Sci., 1999, 15(3), 283.

7. Färber Harald and Schöler Heinz F, J Agric Food Chem., 1993, 41(2), 217-220.

8. Baynes R E and Riviere J E, Am J Vet Res., 1998, 59, 168-175.

9. Chen K.C and Dorough H.W, Drug Chem Toxicol., 1979, 2, 331-354.

10. Toś-Luty S, Latuszyńska J, Halliop J, Tochman A, Przylepa E, Bychawski E and Obuchowska D, Ann Agric Environ Med., 1994, 1, 57-67. 
11. Toś-Luty S, Tokarska-Rodak M, Latuszyńska $\mathrm{J}$ and Przebirowska D, Ann Agric Environ Med., 2001, 8, 47-50.

12. Toś-Luty S, Przebirowska D, Latuszyńska $\mathrm{J}$ and Tokarska-Rodak M, Ann Agric Environ Med., 2001, 8, 137-144.

13. Bhaskara Besagarahally L and Nagaraja Padmarajaiah, E-J Chem., 2006, 3(4), 250-256.

14. Chang S K, Williams P L, Dauterman W C and Riviere J E, Toxicol., 1994, 91, 269280

15. Elderkin S, Wiles R and Campbell C, Fruit Forbidden: Illegal pesticides in the U S food supply, Washington D C, Environmental Working Group, 1995.

16. Howard P H, Handbook of Environmental Fate and Exposure Data for Organic Chemicals, Vol.III.Pesticides, Chelsea, MI, Lewis Publishers, 1991,132.

17. Caldas E D, Coelho R, Souza L.C.K.R and Silva S C, Bull Environ Contam Toxicol., 1999, 62, 199.

18. Harris C A, Human-Exp- Toxical., 1997, 18, 602-606.

19. Waldron Lechner D and Abdel-Rahman M.S, J Toxicol Environ Health, 1986, 18, 241-256.

20. Majidi Mir Reza, Asadpour-Zeynali Karim and Mohammad Nazarpur, J AOAC Int., 2009, 92(2), 548-554.

21. Schaner Angela, Konecny Jaclyn, Luckey Laura and Hickes Heidi, J AOAC Int., 2007, 90(5), 1402-1410.

22. Manirakiza P, Covaci A and Schepens P, Chromatographia, 2000, 52, 787.

23. Cai L, Xing J, Dong L and Wu C, J Chromatogr A, 2003, 1015, 11.

24. Rodrigues M V N, Reyes F G R, Rehder V L G and Rath S, Chromatographia, 2005, 6, 291-297.

25. Lewri S.de Jager and Andrews Anthony R, J Anal., 2000, 125, 1943-1948.

26. Pedrosa Valber A, Caetano Josiane, Machado Sergio A S and Bertotti Mauro, Sensors, 2008, 8, 4600-4610.

27. Kendrick Peter N, Andrew J Trim, Atwal Jaswinder K and Brown Peter M, Bull Environ Contam Toxicol., 1991, 46, 654-661.

28. Sastry C S P, Vijaya D and Mangala D S, Analyst, 1987, 112, 75-78.

29. Bureau of Indian Standard; IS: 7539.

30. Bureau of Indian Standard; IS: 11784:1986 \& IS: 882:1984.

31. Carbaryl: Method 5006, NIOSH manual of Analytical Methods (NMAM), Issue. $2,4^{\text {th }}$ Ed., 1994.

32. Yuen S H, Analyst, 1965, 90, 569-571.

33. Medina J R, Calumpang S M F and Medina M J B, Philippine Agriculturist, 1991, 74(2), 195.

34. Mathew Lata, Reddy M L P, Rao Talasila Prasada, Lyer Chonatumatom S P and Damodaran Alathur D, Analyst, 1995, 120, 1799.

35. Best R J and Hersch N R, J Agric Food Chem., 1964, 12(6), 546-549.

36. Guidance for Industry Q2B Validation of Analytical Procedures: Methodology, ICH November 1996, http://www.fda.gov/cber/guidelines.htm 


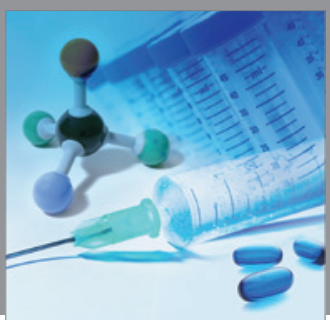

International Journal of

Medicinal Chemistry

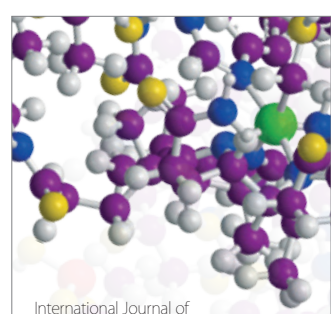

Carbohydrate Chemistry

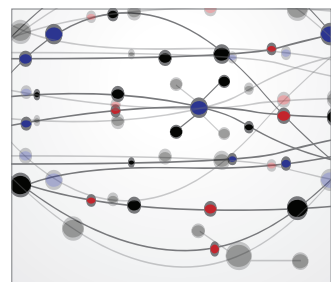

The Scientific World Journal
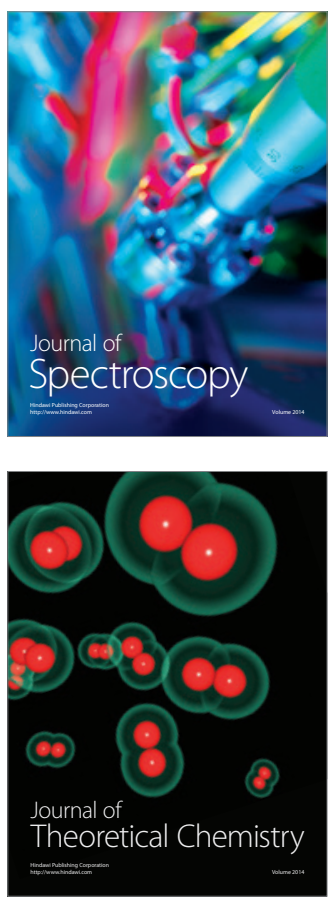
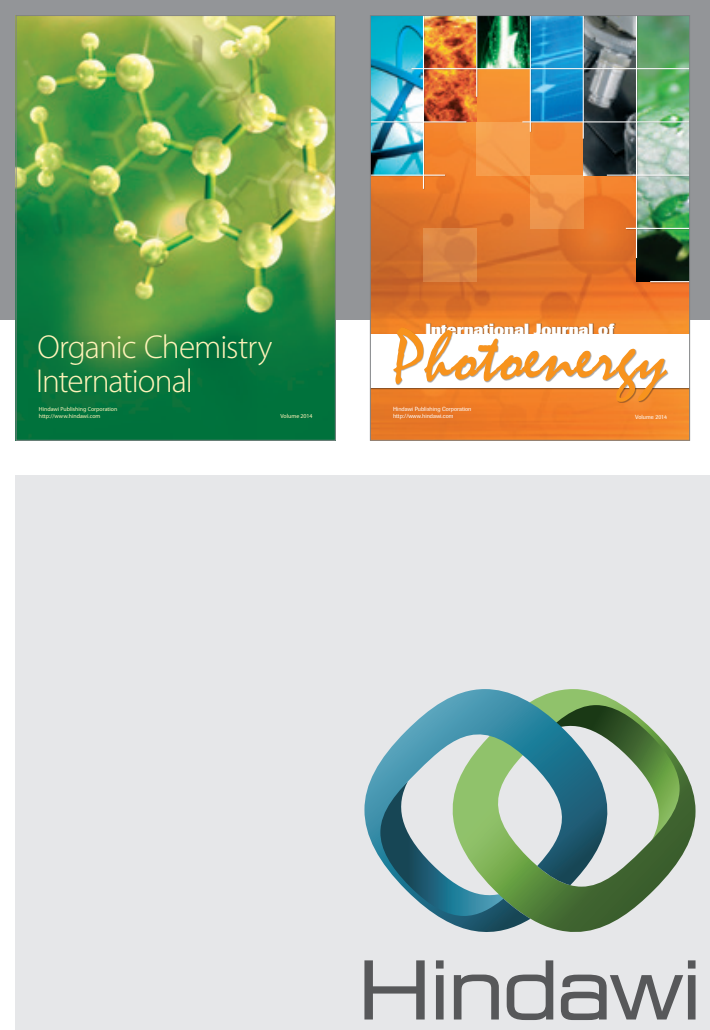

Submit your manuscripts at

http://www.hindawi.com
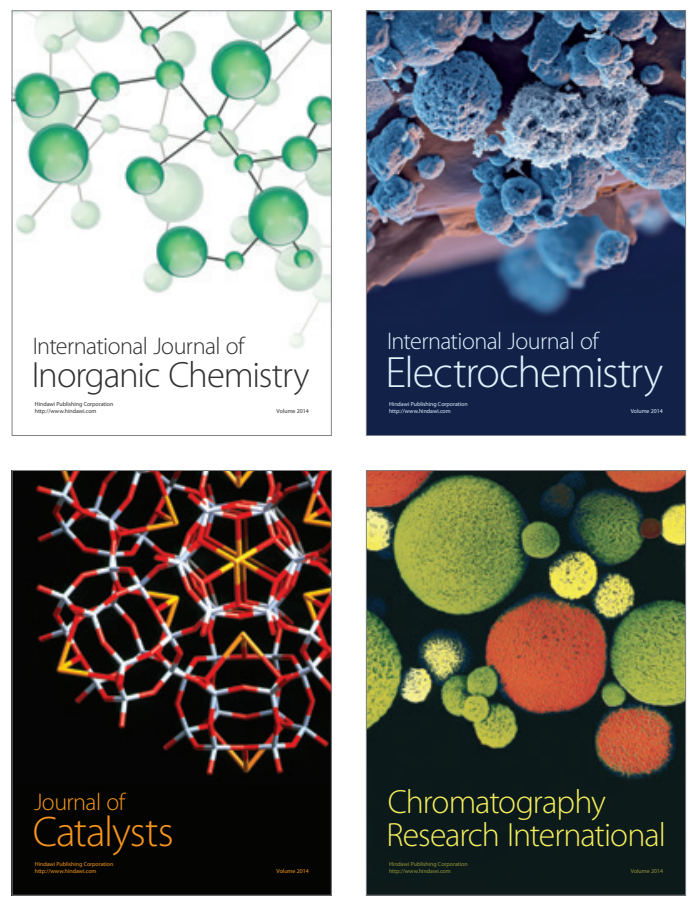
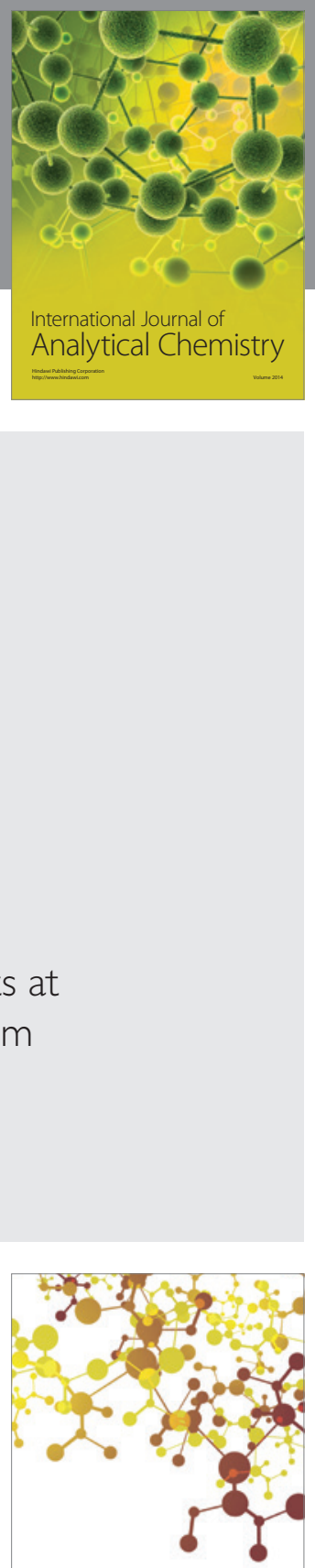

Journal of

Applied Chemistry
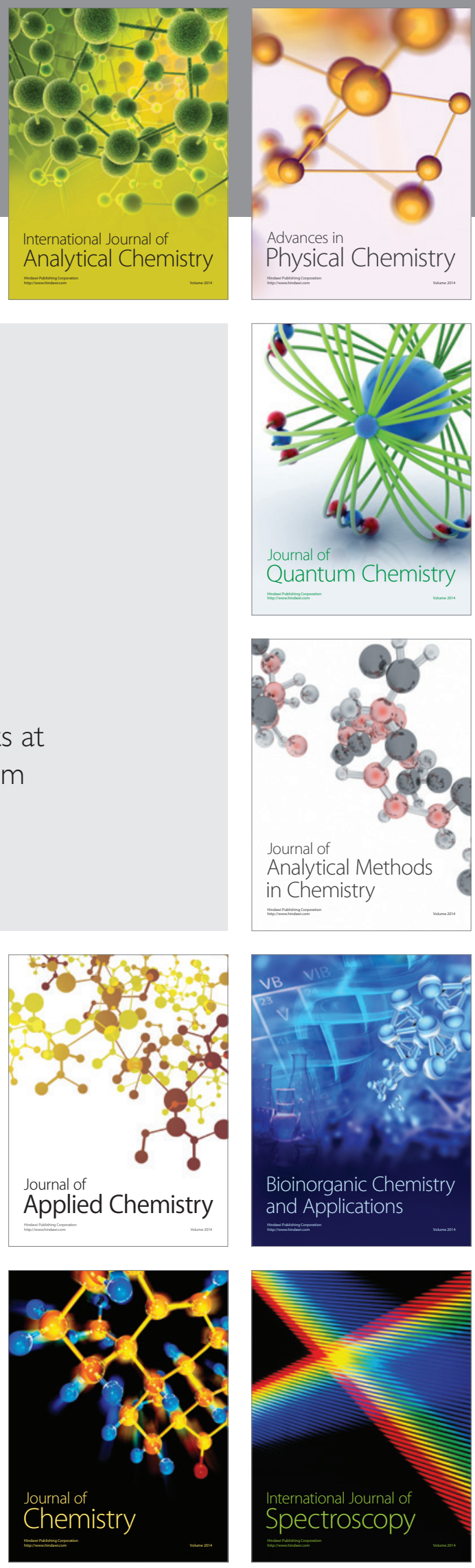